\title{
Development of College of Industrial Technology Frequency Modulation Broadcast Trainer
}

\author{
Bernardo A. Pangilinan \\ Faculty of College of Industrial Technology, Bulacan State University, City of Malolos, Philippines \\ Email: $\underline{\text { b pangilinan ph@yahoo.com }}$
}

Received 20 July 2014; revised 9 September 2014; accepted 12 October 2014

Copyright (C) 2014 by author and OALib.

This work is licensed under the Creative Commons Attribution International License (CC BY).

http://creativecommons.org/licenses/by/4.0/

(c) (i) Open Access

\begin{abstract}
A frequency modulation broadcast station trainer was developed to expose the students to the basic equipment needed in radio broadcasting. The cost of portable FM broadcast trainer is much lower than the cost of the traditional commercially available equipment because of the materials used. The FM broadcast trainer is laboratory equipment that can be used by schools offering academic programs in industrial courses specifically Electronics and Communication Technology courses. At present there is no portable FM broadcast station available in the local market. Some schools are reluctant to buy new FM station equipments since these are quite costly nowadays. To resolve this problem, the researchers deemed that it is necessary to design and develop a portable FM broadcast trainer that is simple and affordable to fulfil the basic curricular requirements for offering courses in Electronics and Communications Technician at Bulacan State University. This is a requirement for the graduates to qualify to take the Radio Telephone Operator examination given by the National Telecommunication Commission, the telecommunication body in the Philippines counterpart of Federal Communication Commission in the US. Aside from this, the station will be a venue for mass communications students and a vehicle for channelling important announcement from the school.
\end{abstract}

\section{Keywords}

Radio, Portable, FM (Frequency Modulation), FM Broadcast Trainer

Subject Areas: Applications of Communication Systems, Information and Communication, Security, Privacy, Trust

\section{Introduction}

The Public Philippine Higher Education System has always been faced with the problem of inadequacy of

How to cite this paper: Pangilinan, B.A. (2014) Development of College of Industrial Technology Frequency Modulation Broadcast Trainer. Open Access Library Journal, 1: e499. http://dx.doi.org/10.4236/oalib.1100499 
equipment. The same problem holds true with the Electronics \& Electronics Communication Department of the Bulacan State University. To address this issue the researchers opted to develop a device that could serve as a radio training station for several applications in electronic communication such as two-way radio communication and FM radio broadcasting. This trainer will equip students with the necessary knowledge in operating basic radio communication equipment and will also develop their skills in manipulating the equipment and applying the proper protocol in radio broadcasting. This will be a great help for them to pass the licensure examination given by the National Telecommunication Commission (NTC). The study will also resolve the problems of acquiring recognition from NTC, the courses offered by the college such as Electronics Technicians and Electronics and Communications Technicians. Since one of the requirements of the NTC to give their recognition to a school is a radio training station, this study is significant. In the light of the inventions mentioned previously in the review and related literatures and studies, the Portable Radio Studio Package and Harris FM Flyaway Package [1] project aims to help remote areas and become an instrument to the people to have an equal distribution of news. It can also help them in the case of emergency when disaster strikes and all the transmission sites go down. This study will also be a vehicle for disseminating important announcement within the university through its low power transmitter and providing musical entertainment by tuning into the frequency of $87.5 \mathrm{Mhz}$. Breaking the barrier of cost of equipment to put up this radio station is also an objective of this study. The study Development of Radio Station (Cruz, K.L., 2010) [2] bought base radio transceiver and single portable transceiver and other assorted devices which cost them about P 50,000. The study will try to significantly reduce the cost of developing this study. The study will seek the appropriate transmitter to transmit signal within the premises of the university. The study will try to utilize old projects of the students such as amplifiers, monitor speakers and FM transmitters to greatly reduce the costs of developing the radio station. The study will also gauge the acceptability of the device by subjecting it to evaluations of students, instructors in electronics and practitioners in FM broadcasting. Using consultation with radio practitioners and instructors teaching the FM broadcasting for decades the researchers will be coming up with cost-efficient and technically sound study. Using questionnaires and interviews from experts the study will be continuously developed through constructive criticisms and feedback.

\section{Data and Method}

In an effort to come up with the study, the conceptual model has been used as a guide in developing the CIT FM broadcast station. Figure 1 cite the conceptualization of the study as further discuss each part.

The INPUTS of the study are the conceptualization taken from similar studies and advised from experts in the field of Radio Broadcasting. Necessary permits were prepared as required by the National Telecommunication Commission such as purchased permit and construction permit. The design of the studio and set-up of equipments was also done during this stage. The equipment and materials as well of its costs have been identified.

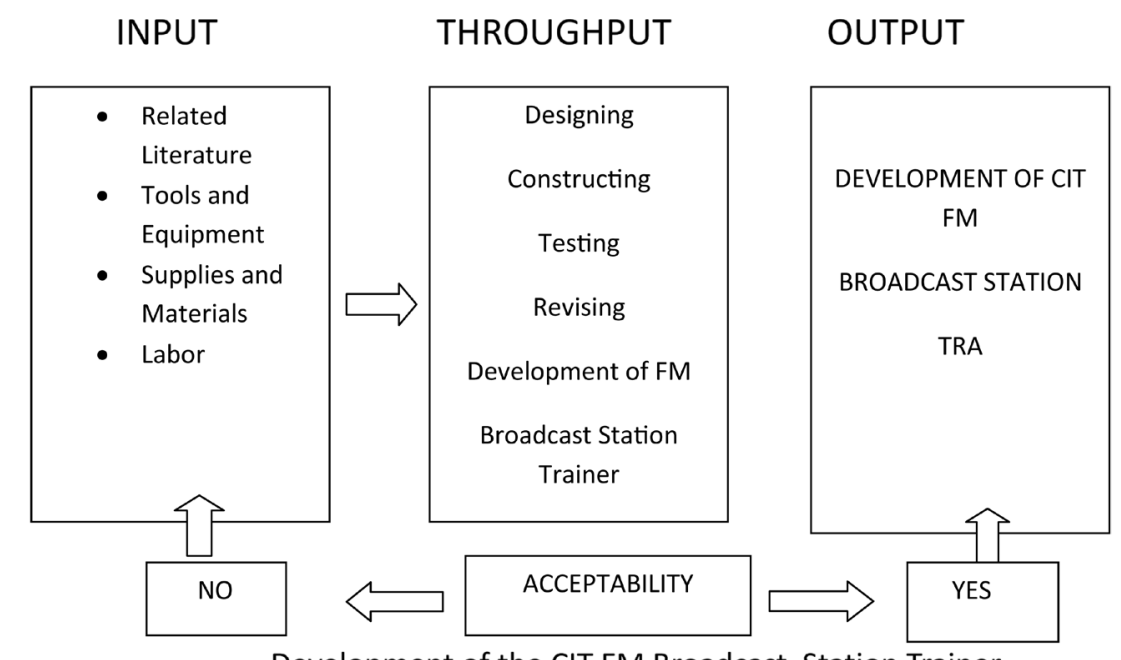

Development of the CIT FM Broadcast Station Trainer

Figure 1. Conceptual model in developing the CIT FM Broadcast Station Trainer. 
The PROCESS composed of constructing the studio and interconnecting the radio equipments as well as fixing the Antenna. Testing and calibration of transmit frequency are also successfully undertaken. After all the equipments have been set-up and calibrated the station was tested and evaluated by faculty handling broadcasting and students of radio operations.

The OUTPUT was the operational FM broadcast station after experts was satisfied and their recommendations were taken into considerations. The project foretold the limitation, conclusion and recommendation of the project.

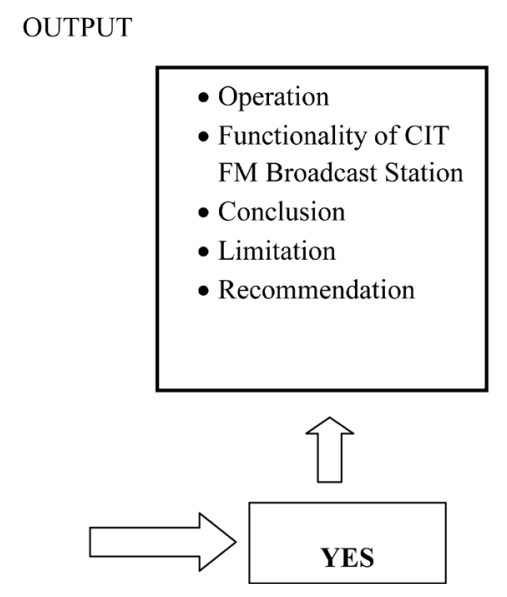

\subsection{Research Method}

To attain the objectives set in the study, the developmental method of research was employed by the researchers.

Developmental Research aims to systematically examine products, tools, processes, and models in order to provide reliable, usable information to both practitioners and theorists. It is intricately connected to real world practice. It creates a loop with practice informing research and research, in turn, informing practice [3].

Specifically the Type 1 developmental study was utilized as the main method for achieving the objectives which is focused upon a given instructional product, program, process, or tool. They reflect an interest in identifying either general development principles or situation-specific recommendations. Typically Type 1 studies address not only product design and development, but evaluation as well. At times they may validate a particular design or development technique or tool.

\subsection{Data Gathering Instruments}

The researcher used evaluation questionnaires to determine the respondent's perception on the acceptability and functionality of the FM broadcast station trainer. The profile of the respondents was shown below.

\subsection{Statistical Treatment of Data}

The weighted mean is used for evaluation of the CIT FM Broadcast Trainer and the boundaries are reflected in Table 1. Table 2 shows the profiles of the respondents from school origin and number of respondents in each school.

\section{Results and Discussion}

The group of evaluators composed of EEC department faculty, engineers, people who are in the field of broadcasting and the beneficiaries were requested to evaluate the acceptability of the FM broadcast station in terms of the following criteria, namely: 1) physical features, 2) cost, 3) durability, and 4) operation.

Figure 2 shows the mechanisms use for mixing and microphone input of the station inside it is the mini low power transmitter.

Figure 3 shows the improvised amplifier and speaker made from previous projects of students in their previous courses. 
Table 1. Weighted mean.

\begin{tabular}{cc}
\hline Scale & Verbal interpretation \\
\hline $4.21-5.00$ & Highly acceptable \\
$3.41-4.20$ & Acceptable \\
$2.61-3.40$ & Moderately acceptable \\
$1.81-2.60$ & Unacceptable \\
$1.0-1.80$ & Highly unacceptable \\
\hline
\end{tabular}

Table 2. Profile of respondents.

\begin{tabular}{cccc}
\hline Teacher Respondent by Schools & Population & Sample Size & Percentage \% \\
\hline Bulacan State University & 12 & 6 & 50 \\
Bulacan Polytechnic College & 3 & 3 & 100 \\
AMA Computer University (Q.C.) & 15 & 15 & 100 \\
Lyceum of the Phil. University (Manila) & 3 & 3 & 100 \\
ABC 5 Engineers (2) & 2 & 2 & 100 \\
TOTAL & 35 & 29 & 83 \\
\hline
\end{tabular}

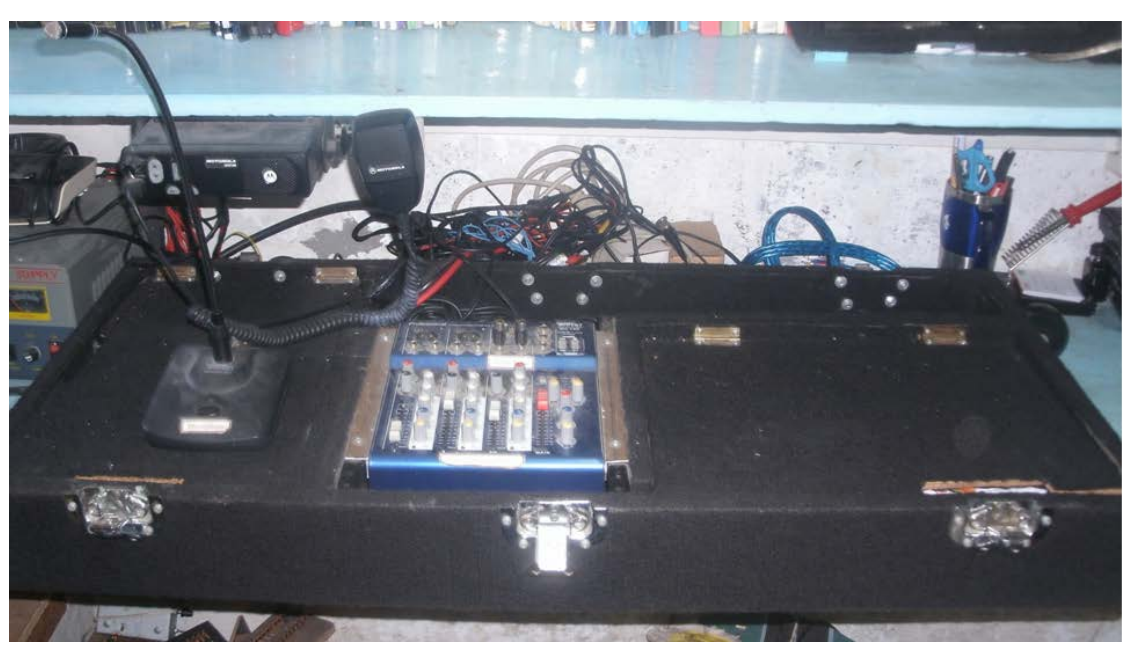

Figure 2. Mixer and console.

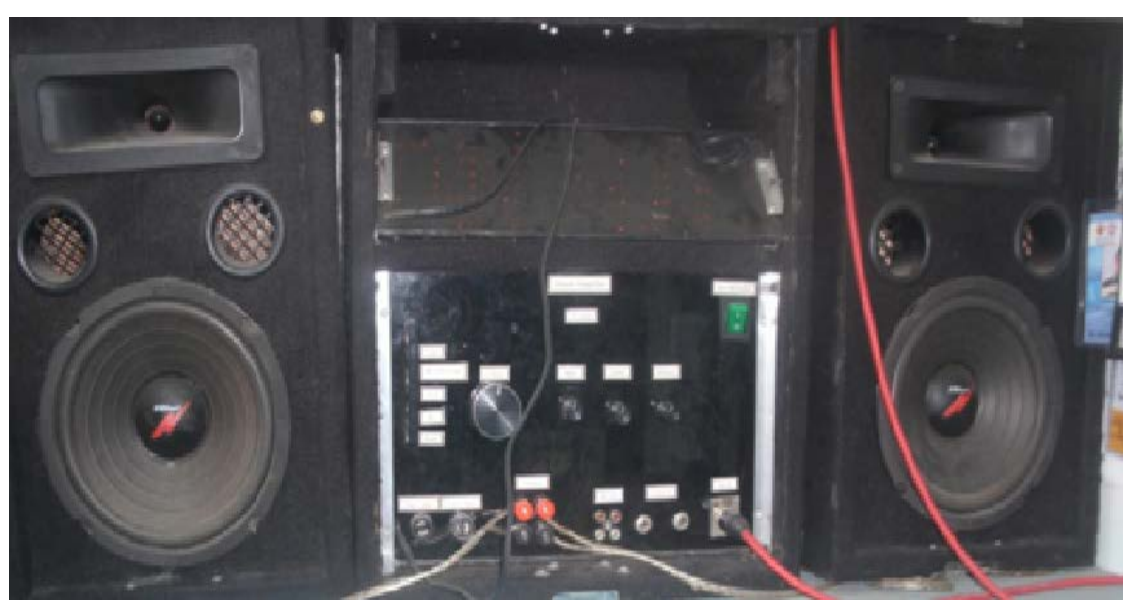

Figure 3. Monitor amplifier. 


\section{Physical Features (Table 3)}

Table 3 shows the criteria in evaluating the physical features of the device. Base on the result of the evaluation, the appearance of the project was generally very acceptable as shown by the computed over all mean of 4.26.

Cost

Table 4 shows the criteria in evaluating the cost and the results of evaluation. The group of the evaluators proved the acceptability of the research project as far as appearance and construction is concerned.

The evaluators strongly agreed, as revealed by the computed mean $=3.36$ for the cost of research study materials used are locally-available with standard quality and some of the materials and components are slightly used to be alternative source to attain reasonable costing. They also strongly agreed on the cost of the trainer unit as cheaper compared to the traditional FM broadcast station.

\section{Durability}

The Table 5 shows the materials used in the FM broadcast station shows durability as revealed an average mean of 4.05 which means that the materials used in very acceptable. As seen by the evaluators from the connectors, cables and to the major equipments.

\section{Operation (Table 6)}

Table 6 shows the criteria in evaluating the device in terms of operating the device easily. The result shows very acceptable with numerical equivalent of 4.36 .

Table 7 shows the over-all mean of evaluation combining all the features of the device and the result was very acceptable.

\begin{tabular}{|c|c|c|}
\hline Physical features & Mean & Interpretation \\
\hline $\begin{array}{l}\text { Physical features workmanship } \\
\text {-the quality imparted to a thing in the process of making. }\end{array}$ & 4.3 & Very acceptable \\
\hline $\begin{array}{l}\text { Acceptability of the circuit sub-assemblies } \\
\text {-easy to use or understand. }\end{array}$ & 4.2 & Very acceptable \\
\hline $\begin{array}{l}\text { Labelling of the parts well presented } \\
\text {-slip of paper, cloth, or other material, marked or inscribed, for } \\
\text { attachment to something to indicate its control and destination. }\end{array}$ & 4.3 & Very acceptable \\
\hline Average & 4.26 & Very acceptable \\
\hline
\end{tabular}

\begin{tabular}{|c|c|c|}
\hline Cost & Mean & Interpretation \\
\hline $\begin{array}{l}\text { Material cost } \\
\text {-an amount paid or required in payment for a purchase. }\end{array}$ & 3.3 & Moderately acceptable \\
\hline $\begin{array}{l}\text { Development cost } \\
\text {-an amount paid for the improvement of the project. }\end{array}$ & 4.0 & Very acceptable \\
\hline Average & 3.36 & Moderately acceptable \\
\hline
\end{tabular}

\begin{tabular}{|c|c|c|}
\hline Durability & Mean & Interpretation \\
\hline $\begin{array}{l}\text { Quality of materials used- } \\
\text {-pre-established measure of the quality of a material, } \\
\text { expressed in physical units. }\end{array}$ & 4.1 & Very acceptable \\
\hline $\begin{array}{l}\text { Rigidity of construction } \\
\text {-the property of a substance that renders it inflexible, } \\
\text { stiff, or no pliable. }\end{array}$ & 4.0 & Very acceptable \\
\hline Average & 4.05 & Very acceptable \\
\hline
\end{tabular}


Table 6. Result of operation.

\begin{tabular}{lcc}
\hline \multicolumn{1}{c}{ Operation } & Mean & Interpretation \\
\hline $\begin{array}{l}\text { Easy to operate/user friendly } \\
\text {-functioning effectively; efficient. }\end{array}$ & 4.17 & Very acceptable \\
$\begin{array}{l}\text { Absence of the risk of electric shock } \\
\text {-the danger or probability of loss to an insurer. }\end{array}$ & 4.3 & Very acceptable \\
$\begin{array}{l}\text { Low maintenance need } \\
\text {-not needing much effort or money. }\end{array}$ & 4.1 & Very acceptable \\
\multicolumn{1}{c}{ Average } & $\mathbf{4 . 3 6}$ & Very acceptable \\
\hline
\end{tabular}

Table 7. Over-all mean and descriptive rating of the evaluation of the acceptability of the device.

\begin{tabular}{lcc}
\multicolumn{1}{c}{ Criteria } & Mean & Descriptive rating \\
\hline a) Physical features & 4.26 & Very acceptable \\
b) Cost & 3.36 & Moderately acceptable \\
c) Durability & 4.05 & Very acceptable \\
d) Operation & 4.36 & Very acceptable \\
Total & $\mathbf{4 . 0 0 8}$ & Very acceptable \\
\hline
\end{tabular}

\section{Conclusions}

Based on the foregoing findings the following conclusions were drawn:

1) The transmitter used is capable to operate within the vicinity of the campus around $300 \mathrm{~m}$ radius and at 87.5 Mhz provided without any physical obstructions, which prohibits line of sight transmissions.

2) The equipments used are previous projects of the students to minimize the cost of the station.

3) The dimensions of the radio room are based on NTC standards and it is located in the third floor of the CIT Building of BSU.

4) Based on the evaluation of the respondent experts, the device is deemed to be very acceptable.

5) The program Bachelors in Industrial Technology major in Electronics and Communications Technology gained its recognition from National Telecommunication Commission after submitting all the documentary requirements and investigations of the facility.

6) The graduates of the program may now allow taking the radio telephone operator examination given by NTC.

\section{References}

[1] AM/FM Radio Flyaway Portable Broadcast System (2012).

http://oleafrica.com/recent-post/portable-fm-radio-station-put-together-by-a-kenyan-canadian-peter-onguti/1389

[2] Cruz, K.L. (2010) Development of Radio Station. Unpublished Theses, CIT-Bulacan State University, Malolos City.

[3] Richey and Klein (2005) Developmental Study Concepts. 